\title{
Splenic infarction as a complication of laparoscopic sleeve gastrectomy
}

\author{
Maciej Michalik ${ }^{1}$, Roman Budziński ${ }^{1}$, Michał Orłowski ${ }^{1}$, Agata Frask ${ }^{1}$, Maciej Bobowiczz, Anna Trybull ${ }^{1}$, Paweł Lech', \\ Maciej Pawlak ${ }^{1}$, Konrad Szydłowski ${ }^{1}$, Grzegorz Wallner ${ }^{2}$ \\ ${ }^{1}$ General and Vascular Surgery Department, Ceynowa Hospital, Wejherowo, Poland \\ $2^{\text {nd }}$ Department of General Surgery, Medical University Hospital of Lublin, Lublin, Poland
}

Videosurgery and other miniinvasive techniques 2011; 6 (2): 92-98

DOI: 10.5114/wiitm.2011.23216

\begin{abstract}
Introduction: Laparoscopic sleeve gastrectomy (LSG) as a stand-alone or a first step in the biliopancreatic diversionduodenal switch (BPD-DS) procedure is frequently the surgery of choice for the 21st century's epidemic of morbid obesity. To date, LSG as a relatively new method has few complications reported and analysed.

Aim: The article describes splenic infarction, not reported so far, a potentially serious complication of LSG, analyses its causes, and suggests a considerate treatment and follow-up protocol.

Material and methods: During the observation period between March and November 2008, 24 LSG patients (20 female and 4 male) were enrolled with mean body mass index of $44 \mathrm{~kg} / \mathrm{m}^{2}$. All LSG procedures were recorded. Computerized statistical software Statistica 7 StatSoft, Krakow, Poland was used for analysis. Statistical significance was calculated with nonparametric tests $(p<0.05)$.

Results: In 4 patients (17\%) splenic infarction was diagnosed intraoperatively. Consecutive angio-CT scan confirmed infarction of the upper splenic pole with 12\% to 33\% of the splenic pulp affected. Two out of 4 patients had one minor perioperative complication. There were no significant differences between patients. Video analysis excluded possible technical errors.

Conclusions: The described analysis suggests short gastric vessels and upper terminal splenic artery branch dissection as possible causative factors of splenic infarction in the course of LSG. We suggest a considerate protocol with abdominal cavity inspection at the beginning and end of the procedure, angio-CT scans, prophylactic LMWH, initial broad spectrum intravenous antibiotics, and appropriate follow-up with neither splenectomy nor related immunization.
\end{abstract}

Key words: splenic infarction, laparoscopic sleeve gastrectomy

\section{Introduction}

Morbid obesity is often called the first global epidemic of the twenty-first century [1]. As in all epidemics, obesity raises wide concerns and represents a great challenge for current medical practice. Conservative therapy of obesity is based on pharmacological and behavioural strategies which as well as dietary regimens are believed to have limited effec- tiveness. After many years of limited success, surgery is now considered to be one of the main methods of effective and durable treatment of obese patients [2]. One of the surgical interventions that has been proved to be effective in bariatric surgery is sleeve gastrectomy (SG). This was developed in the 1990s and was first described by Hess and Marceau et al. [3, 4]. In 1999 Ganger performed the first laparoscopic sleeve gastrectomy (LSG) and a year later he sugges- 
ted this procedure to be the first stage in treatment of patients with a body mass index (BMI) higher than $60 \mathrm{~kg} / \mathrm{m}^{2}[5,6]$. Laparoscopic sleeve gastrectomy was adopted in 2003 as an initial surgical intervention of choice for patients with super morbid obesity (BMI greater than $50 \mathrm{~kg} / \mathrm{m}^{2}$ ). The LSG induced rapid body mass loss and distinctly improved the technical capabilities of a final procedure, such as gastric bypass or duodenal switch. Recently, numerous data have supported the treatment of obesity with LSG as a stand-alone and final procedure, because of its good results and permanent effects. Nowadays such a view is supported by numerous health care professionals [7-10].

\section{Material and methods}

The LSG procedure was introduced in the Department of General and Vascular Surgery of Ceynowa Hospital, Wejherowo, Poland in January 2006, after several years of experience with other bariatric and general surgical laparoscopic procedures.

During the observation period between March 2006 when the first splenic infarct was recorded intraoperatively and November 2008, a total of 24 LSG due to morbid obesity were performed after obtaining informed consent. Twenty women and 4 men were enrolled with a mean BMI of $44 \mathrm{~kg} / \mathrm{m}^{2}$. In 2 patients LSG was performed as the second stage treatment, after failure of laparoscopic gastric banding. All patients received a subcutaneous enoxaparin sodium injection (40 mg) $12 \mathrm{~h}$ prior to procedure and intravenous antibiotic prophylaxis with $1.2 \mathrm{~g}$ of amoxicillin-clavulanate directly before the procedure.

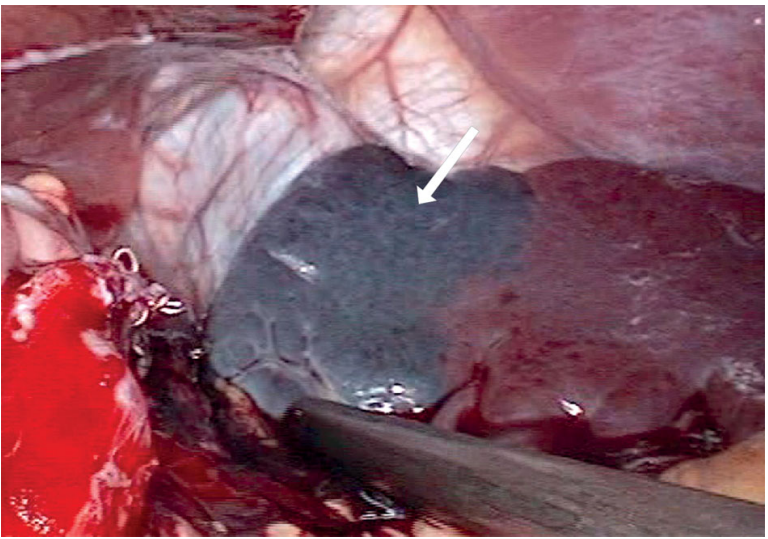

Figure 1. Splenic infarction recognised intraoperatively (arrow points to the infarcted splenic pulp)
All LSG were recorded on a DVD disc for later review. When intraoperative disturbance of the splenic blood supply was noted (Figure 1), an angio-CT was performed the day following surgery (Figure 2). Each patient with radiologically confirmed splenic infarction was empirically given intravenous antibiotic treatment with amoxicillin-clavulanate $1.2 \mathrm{~g}$ three times a day for the length of the hospital stay. These patients were also given clinic review appointments, 7 days, 28 days and 3 months after surgery.

\section{Surgery technique}

The procedures were performed with five trocars (three $11 \mathrm{~mm}$ and two $5 \mathrm{~mm}$ trocars) placed in the epigastric region. After dissection of the omental sac, the greater curvature was freed by section of the gastrocolic ligament very closely to stomach surface, starting $6 \mathrm{~cm}$ from the antrum up to the angle of His using a $5 \mathrm{~mm}$ harmonic scalpel (Harmonic ACE ${ }^{\circledR}$ Curved Shear Ethicon Endo-Surgery, Inc.). The short gastric vessels were clipped when necessary. Longitudinal gastric resection of the fundus and greater curvature was performed using the linear stapler system (Echelon ${ }^{\text {TM }} 60$ ENDOPATH ${ }^{\circledR}$ Stapler Ethicon Endo-Surgery, Inc.) Occasional bleeding from the staple line was controlled using single hand-tied sutures. During every procedure the condition of the spleen was assessed twice: firstly when examining the peritoneal cavity at the beginning of the procedure, and secondly after removal of the excised part of the stomach before abdominal closure.

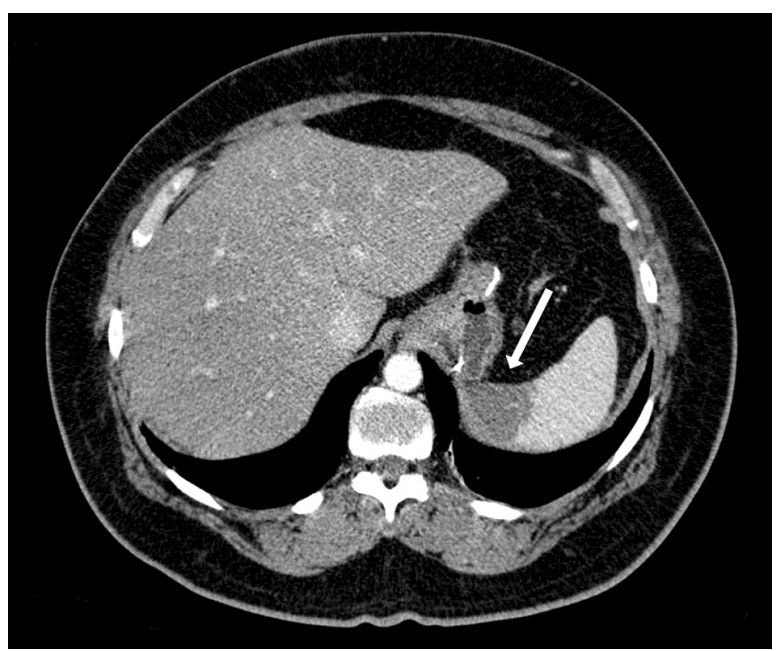

Figure 2. CT-angiography scan of splenic infarction (arrow points to the infarcted splenic pulp) 


\section{Results}

In the 24 patients treated by the LSG method since March 2008, 4 patients (16.6\%), all female (no co-morbidities), were diagnosed with an infarct of the upper splenic pole. All splenic infarcts were diagnosed intraoperatively and then confirmed radiologically using angio-CT. This identified infarction of the upper splenic pole involving $12 \%$ to $33 \%$ of the total splenic pulp. Analysis of the course of treatment has shown no significant differences between patients with splenic infarct and the group with no complications. Video analysis of all performed procedures excluded the possibility of technical failure. However, this analysis identified that short gastric vessels and dissection of the upper terminal splenic artery branch whilst mobilising the stomach's greater curvature represented likely causative factors of splenic segmental infarction. No major differences could be identified when comparing the group characteristics of splenic infarct patients with those who did not develop complications (Table I).

One of the patients with iatrogenic post-LSG splenic infarction complained of pain in the left hypochondrium which radiated to the left loin, during the first $24 \mathrm{~h}$ following the procedure. There were no other complications following LSG in the group of 24 patients. Both on the day of the discharge, and during the routine follow-up appointments until the present time, none of the patients presented symptoms related to splenic infarction, either surgical or infective. To date no deaths have been recorded.

\section{Discussion}

Laparoscopic sleeve gastrectomy provides not only a restrictive mechanism by reducing the intake

Table I. Comparison of patient groups

\begin{tabular}{|lcc|}
\hline & $\begin{array}{c}\text { No complications } \\
\text { group }\end{array}$ & $\begin{array}{c}\text { Splenic infarct } \\
\text { group }\end{array}$ \\
\hline Number & 20 & 4 \\
\hline Mean age [years] & $34.80(20-50)$ & $34.25(25-46)$ \\
\hline Mean surgery time [min] & $75.52(45-95)$ & $47.50(45-50)$ \\
\hline $\begin{array}{l}\text { Mean hospitalization } \\
\text { time [days] }\end{array}$ & $3.94(2-6)$ & 3 \\
\hline Mean BMI [kg/m²] & 42.68 & 42.40 \\
\hline Prior abdominal surgery & $10(50 \%)$ & $2(50 \%)$ \\
\hline
\end{tabular}

of excessive food, but also causes a decrease in ghrelin serum concentration and causes a statistically significant reduction in hunger sensation when compared with other bariatric procedures [4, 11-13].

Laparoscopic sleeve gastrectomy like other similar procedures includes some risk. To date, the following complications of LSG have been described in the available literature [6, 8, 10, 14-18]:

- staple line leakage,

- stricture of the created tube,

- dilatation of the created tube,

- haemorrhage from the short gastric vessels or staple line,

- trocar site bleeding,

- splanchnic vessel thrombosis,

- pulmonary embolism,

- delayed stomach emptying,

- intraperitoneal abscess,

- iatrogenic splenic injury,

- postoperative wound infection,

- postoperative hernia.

The perioperative mortality after LSG is reported at levels of up to $0.6 \%[14,15]$.

When the first splenic infarct during LSG was diagnosed, we conducted a comprehensive literature search using the following search engines, databases and websites: PubMed, the Cochrane Library, EBSCO, ProQuest/Medline, Embase, ScienceDirect, Wiley InterScience, and Medpilot. The key words used were: surgery, laparoscopy, bariatry, obesity, iatrogenic, complication, sleeve resection, sleeve gastrectomy, splenic infarct, laparoscopic sleeve resection, and laparoscopic sleeve gastrectomy, as well as combinations of the above words and MeSH terms. The search did not identify any previous descriptions of splenic infarct as a complication of sleeve gastrectomy. Splenic infarction in bariatric patients has potentially serious consequences. In the absence of case reports in the medical literature, we deemed it necessary to analyse and present the frequency of splenic infarction in our own material.

As mentioned above, to date there have been no reports of post-LSG splenic infarcts. In general, splenic infarct is a rare pathology, described usually as a complication of left upper quadrant abdominal surgery or minimally invasive procedures e.g. colonoscopy, and has been shown to be associated with a heterogeneous group of medical conditions (collated in Table II) [19-26]. 
The LSG is impeded by the close proximity of the upper part of the stomach body, its fundus and the spleen. The procedure is further complicated by the diverse course of vessels running within the stomach's ligaments, which are dissected during the surgery. The left and right gastric arteries supply the lesser curvature of the stomach. In contrast, the greater curvature of the stomach derives its arterial blood supply from three to six short gastric arteries running through the gastrophrenic ligament and the upper part of the gastrosplenic ligament up to the splenic hilum, also providing blood supply to the upper pole of the spleen. The remaining part of the greater curvature is supplied by anastomosed gastroepiploic arteries known as Hyrtl's arterial arc and their branches, run-

Table II. Causes of splenic infarction

\begin{tabular}{|c|c|}
\hline \multirow[t]{8}{*}{ Surgical } & Total gastrectomy \\
\hline & Antrectomy \\
\hline & Vagotomy \\
\hline & Hemicolectomy \\
\hline & Salpingectomy \\
\hline & Pancreatic resections \\
\hline & Liver transplantation \\
\hline & Oesophagectomy \\
\hline \multirow[t]{7}{*}{ Haematological } & Leukaemia \\
\hline & Myelofibrosis \\
\hline & Lymphoma \\
\hline & Sickle cell anaemia \\
\hline & Sickle cell trait \\
\hline & Haemoglobin SC disease \\
\hline & Polycythemia vera \\
\hline \multirow[t]{6}{*}{ Infectious } & Mononucleosis \\
\hline & AIDS \\
\hline & Malaria \\
\hline & Disseminated varicella \\
\hline & Sepsis \\
\hline & Pyelonephritis \\
\hline
\end{tabular}

ning in the gastrosplenic and gastrocolic ligaments. The gastroepiploic arteries usually occur about $1-2 \mathrm{~cm}$ from the stomach wall. Their course is tortuous and shows high individual variability. In general, there is considerable anastomotic communication between the stomach arteries and the blood supply systems of other organs such as the spleen, oesophagus, adrenaIs and diaphragm (Figure 3) [27].

Physiologically, splenic segmental arteries are terminal arteries without any collateral circulation. Therefore, closure of a segmental artery usually leads to infarction of the vascularised splenic segment or splenic pole. The possible anatomical variants of upper splenic pole arterial blood supply are shown in Figure $4[28,29]$.

\begin{tabular}{|c|c|}
\hline \multirow[t]{2}{*}{ Traumatic } & $\begin{array}{l}\text { Blunt and penetrating } \\
\text { abdominal trauma }\end{array}$ \\
\hline & $\begin{array}{l}\text { Chest trauma (especially of the } \\
\text { left side) }\end{array}$ \\
\hline \multirow[t]{2}{*}{ Cardiac } & Endocarditis \\
\hline & Valvular diseases \\
\hline \multirow[t]{5}{*}{ Vascular } & $\begin{array}{l}\text { Superior mesenteric artery or } \\
\text { coeliac axis thromboembolism }\end{array}$ \\
\hline & Portal vein or splenic vein thrombosis \\
\hline & Cirrhosis with portal hypertension \\
\hline & Atherosclerosis \\
\hline & Aortic aneurysms \\
\hline \multirow{2}{*}{$\begin{array}{l}\text { Connective tissue } \\
\text { diseases }\end{array}$} & SLE \\
\hline & Polyarteritis nodosa \\
\hline \multirow[t]{4}{*}{ Drugs } & Cocaine \\
\hline & Vasopressin \\
\hline & Erythropoietin \\
\hline & Clofazimine \\
\hline \multirow[t]{5}{*}{ Others } & Sarcoidosis \\
\hline & Amyloidosis \\
\hline & Wegener's granulomatosis \\
\hline & Pancreatitis or pancreatic cancer \\
\hline & Gaucher's disease \\
\hline
\end{tabular}


The majority of patients with partial splenic infarcts have an asymptomatic or mildly symptomatic clinical course usually without significant complications and do not typically require surgical treatment. In these cases conservative management of the associated symptoms is usually adequate. Specifically, antibiotics, analgesia, intravenous fluids and anticoagulation may be required depending on the status of the patient. Occasionally there is a need for transfusion of blood products. Sometimes, a splenic infarct undergoes fibrosis of the malperfused segment or leads to complications such as the development of a haematoma, splenic rupture, abscess, or pseudocyst formation [30]. In such cases surgical intervention should be considered. There is an ongoing discussion concerning the advantages and disadvantages of partial and total splenectomy in these patients, but at the present time there is no consensus on the patient management guidelines [31, 32].

Widespread splenic infarctions are associated with potentially serious immunological and haema-

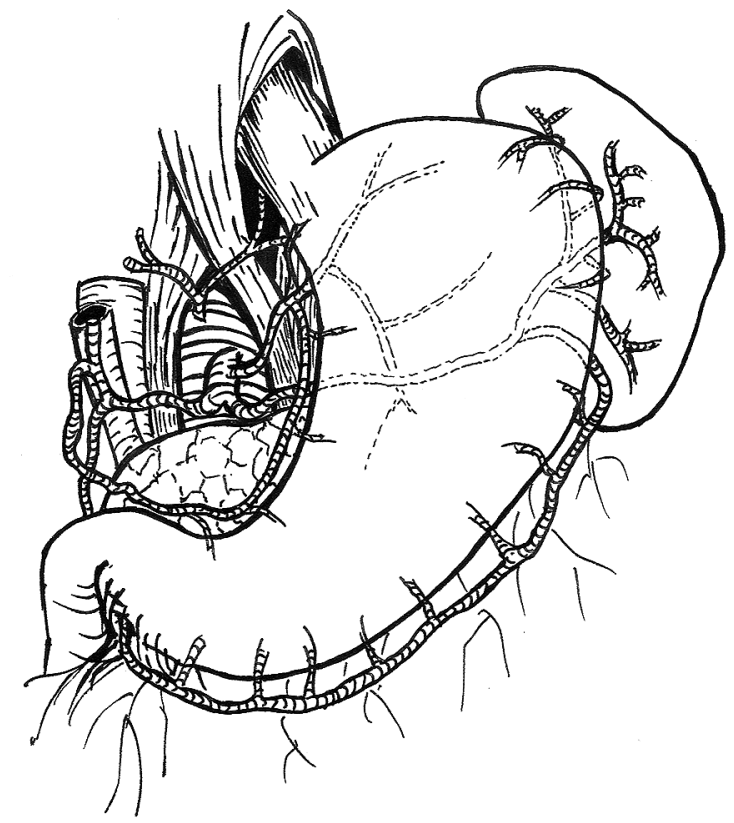

Figure 3. Arterial blood supply of stomach and spleen
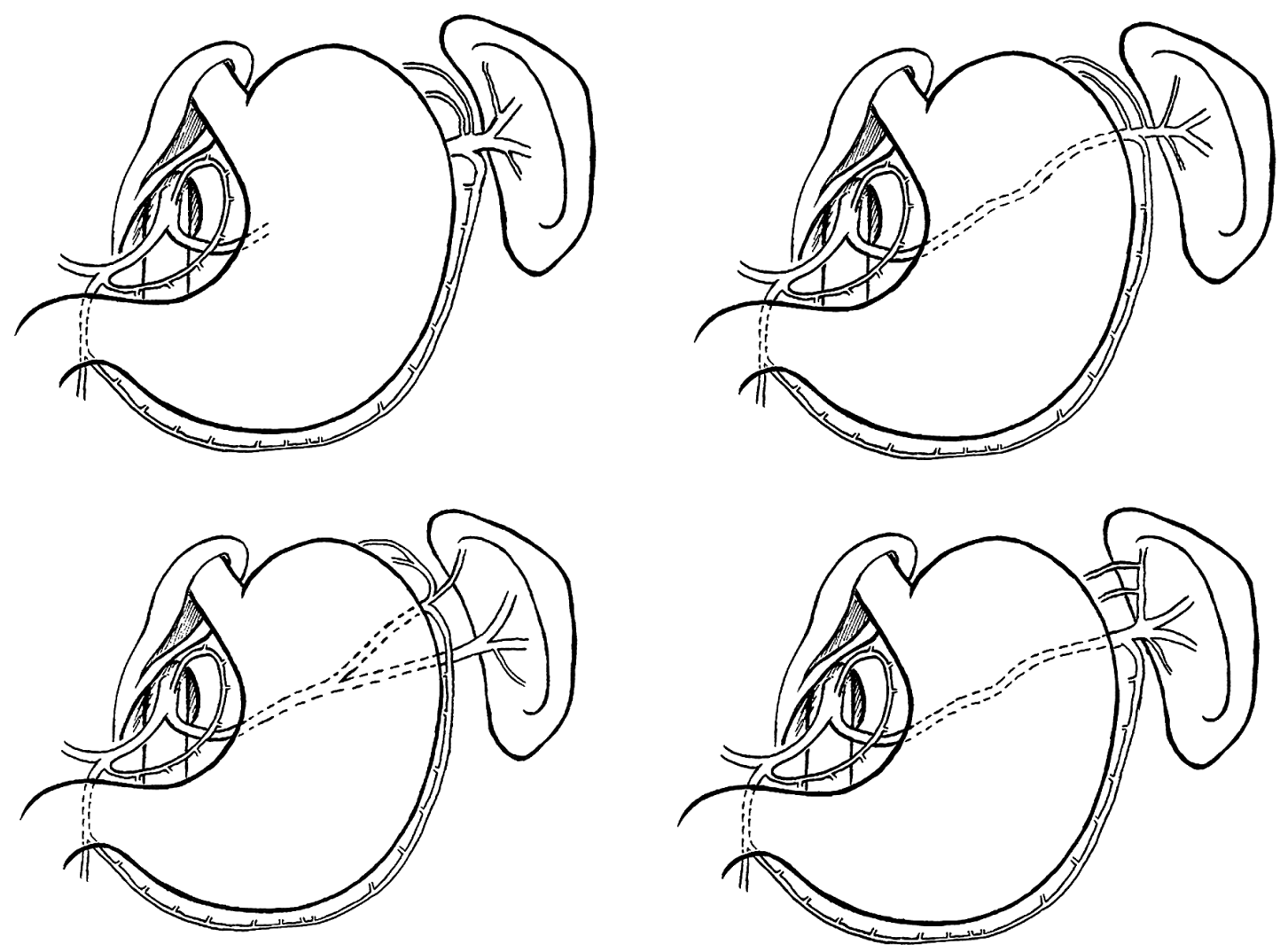

Figure 4. Variants of upper splenic pole arterial blood supply 
tological implications. Affected patients require frequent and regular haematological tests in addition to necessary immunisations including meningococcus, pneumococcus and haemofilus influenzae vaccinations with prolonged prophylactic antibiotic treatment [31-33].

In the presented cases only one or two upper pole splenic segments were observed to be affected. Only minor complications such as nausea, vomiting and left epigastric pain were encountered by two patients during the first postoperative day and no subsequent late complications were observed. All affected patients received antibiotic prophylaxis during the perioperative period, though there were no other specific alterations to their medical treatment. The patients in this study who encountered splenic infarction during LSG did not develop sufficiently widespread damage to require splenectomy or further operative intervention. The only extra measure taken in this group was the use of angio-CT to investigate the extent of splenic infarction. All patients were assigned to regular outpatient follow-up to monitor their clinical status and introduce appropriate treatment if required. We decided not to immunise our patients as the infarcts they developed were relatively small, with the largest accounting for 33\% of the total splenic pulp.

In Poland, there are only a few bariatric centres, so some of the patients are hospitalised longer for social reasons (to ensure full recovery before long travel back home). That explains the situation of longer hospitalization periods in some of the patients with no complications.

\section{Conclusions}

Based on the observations we conclude that splenic infarction is an under-reported and frequent complication of laparoscopic sleeve gastrectomy as well as many other laparoscopic procedures. We observed that splenic infarction occurred in $16.6 \%$ of these procedures performed at a longstanding laparoscopic surgical centre. We believe that the presence of splenic infarction in obese subjects is under-diagnosed due to the spleen's location (usually behind the stomach, covered with intra-abdominal fat) and lack of guidelines on detailed inspection of the abdominal cavity after the procedure with little emphasis currently being placed on the status of the spleen.
Retrospective analysis of video recordings of the relevant LSG ruled out technical errors as the cause of splenic infarction. However, this analysis identified that short gastric vessels and dissection of the upper terminal splenic artery branch whilst mobilising the stomach's greater curvature represented likely causative factors.

The collective experience at the centre led us to create a rule of detailed abdominal cavity inspection with special emphasis on the spleen at the beginning and at the end of every procedure as well as a local protocol for patients with intraoperatively recognised splenic upper pole infarction which comprises:

- angio-CT scan the day following the procedure to assess the extent of splenic pulp damage and at 3 months if symptomatic,

- low molecular weight heparin in thrombo-prophylactic doses,

- if asymptomatic - regular discharge,

- review and follow-up on the $7^{\text {th }}$ and $28^{\text {th }}$ day and the $3^{\text {rd }}$ month after surgery,

- no splenectomy and no related immunization in cases of infarct $<33 \%$ of total splenic pulp.

Further evaluation of the above protocol on a larger group of patients is currently underway. We hope that other centres will share their experience in this matter to enable coprocedure on improving the outcomes and safety of laparoscopic sleeve gastrectomy as one of the few effective treatments for morbid and super morbid obesity.

\section{Acknowledgments}

The authors would like to thank and acknowledge the work and contribution to the article of Alexander Kidd MD, PhD.

\section{References}

1. WHO. Obesity: preventing and managing the global epidemic. Report of a WHO Consultation. WHO Technical Report Series 894. Geneva: World Health Organization, 2000. Available at: http://www.who.int/bmi/index.jsp

2. Elder KA, Wolfe BM. Bariatric surgery: a review of procedures and outcomes. Gastroenterology 2007; 132: 2253-71.

3. Hess DS, Hess DW. Biliopancreatic diversion with a duodenal switch. Obes Surg 1998; 8: 267-82.

4. Marceau P, Hould FS, Simard S, et al. Biliopancreatic diversion with duodenal switch. World J Surg 1998; 22: 947-54.

5. Gagner M, Patterson E. Laparoscopic biliopancreatic diversion with duodenal switch. Dig Surg 2000; 17: 547-66. 
6. Deitel M, Crosby RD, Gagner M. The First International Consensus Summit for Sleeve Gastrectomy, New York City, October 25 27, 2007. Obes Surg 2008; 18: 487-96.

7. Kueper M, Kramer K, Kirschniak A. Laparoscopic sleeve gastrectomy: standardized technique of a potential stand-alone bariatric procedure in morbidly obese patients. World J Surg 2008; 32: 1462-5

8. Felberbauer FX, Langer F, Shakeri-Manesch S, et al. Laparoscopic sleeve gastrectomy as an isolated bariatric procedure: intermediate-term results from a large series in three Austrian centers. Obes Surg 2008; 18: 814-8.

9. Iannelli A, Dainese R, Piche T, et al. Laparoscopic sleeve gastrectomy for morbid obesity. World J Gastroenterol 2008; 14: 821-7.

10. Msika S (ed.). Laparoscopic sleeve gastrectomy: the gold standard for tomorrow? Proceedings of the Joint Meeting Societe Francaise Chirurgie Endoscopique and Mediteeanean \& Middle Eastern Surgery Association 2008 Nov 13-15, Bordeaux, France.

11. Langer F, Reza Hoda M, Bohdjalian A, et al. Sleeve gastrectomy and gastric banding: effects on plasma ghrelin levels. Obes Surg 2005; 15: 1024-9.

12. Lin E, Gletsu N, Fugate K, et al. The effects of gastric surgery on systemic ghrelin levels in the morbidly obese. Arch Surg 2004; 139: 780-4.

13. Karamanakos SN, Vagenas K, Kalfarentzos F, et al. Weight loss, appetite suppression, and changes in fasting and postprandial ghrelin and peptide-YY levels after Roux-en-Y gastric bypass and sleeve gastrectomy: a prospective, double blind study. Ann Surg 2008; 247: 401-7.

14. Gumbs A, Gagner M, Dakin G, et al. Sleeve gastrectomy for morbid obesity. Obes Surg 2007; 17: 962-9.

15. Lalor PF, Tucker ON, Szomstein S, et al. Complications after laparoscopic sleeve gastrectomy. Surg Obes Relat Dis 2008; 4: 33-8.

16. Kral JG, Näslund E. Surgical treatment of obesity. Nat Clin Pract Endocrinol Metab 2007; 3: 574-83.

17. Kolomecki K, Cywinski J, Bartnicki J, et al, Hydrothorax as a complication of upper abdominal surgery. Videosurgery 2006; 2: 59-64.

18. Baltasar A, Serra C, Pérez N, et al. Re-sleeve gastrectomy. Obes Surg 2006; 16: 1535-8.

19. Beeson MS. Splenic infarct presenting as acute abdominal pain in an older patient. J Emerg Med 1996; 14: 319-22.

20. Vanhoenacker FM, De Beeck B, De Schepper AM, et al. Vascular disease of the spleen. Seminars in Ultrasound, CT, and MR 2007; 28: 35-51

21. Uranus S, Alimoglu O. Invited Commentary to: Splenic abscess and infarction-rare events for which surgery is mandatory. Eur Surg 2003; 35: 326.

22. Guth AA, Pachter HL. Splenic infarct. Available at: http://emedicine.medscape.com/article/193718-overview. Accessed May 21, 2009.

23. Gupta S, Kakar A. Splenic infarct of unusual aetiology. JIACM 2004; 5: 310-4.

24. Yavasoglu I, Kadikoylu G, Bolaman Z. Recovery of splenic infarction with anti-platelet treatments and platelet-apheresis in polycythemia vera. Transfus Apher Sci 2006; 34: 199-202.

25. Gayer G, Galperin-Aizenberg M. Iatrogenic splenic injury in postoperative patients: a series of case reports. Emerg Radiol 2008; 15: 109-13.
26. Gmeiner M, Pfeifer J. Management of complications in surgery of the colon. Eur Surg 2007; 39: 15-32.

27. Borley NR. Abdominal viscera - spleen. In: Standring S (ed.). Grey's anatomy. 39th edition. Churchill Livingstone, 2008.

28. Klepac SR, Samett EJ. Spleen trauma. Available at: http://emedicine.medscape.com/article/373694-overview. Accessed May 21, 2009.

29. Gregorczyk M, Dabkowska A, Tarka S, et al. The anatomy of the fundic branches of the stomach: preliminary results. Folia Morphol 2008; 67; 2: 121-5.

30. Arruabarrena A, Azagra JS, Wilmart JF, et al. Unusual complication after laparoscopic left nephrectomy for renal tumour: a case report. Videosurgery and other miniinvasive techniques 2010; 5: 60-4.

31. Katz SC, Pachter HL. Indications for Splenectomy. Am Surg 2006; 72: 565-80.

32. Habermalz B, Aauerland S, Decker G et al. Laparoscopic splenectomy: the clinical practice guidelines of the European Association for Endoscopic Surgery (EAES). Surg Endosc 2008; 22: 821-48.

33. Dzielicki J, Grabowski A, Korlacki W. Optimizing the technique of laparoscopic splenectomy in children. Videosurgery and other miniinvasive techniques 2010; 5: 19-26. 